\title{
Numerical-Experimental characterization of honeycomb sandwich panel and numerical modal analysis of implemented delamination
}

\author{
Aya Bendada, Djilali Boutchicha, Adel Chouiter, Mokhtaria Miri \\ Université des Sciences et de la Technologie d'Oran - Mohamed Boudiaf, USTO-MB, Algérie. \\ aya19-23-05@hotmail.fr(aya.bendada@univ-usto.dv),boutchicha@hotmail.com, achouiter25@gmail.com,m_miri31@yahoo.fr
}

\begin{abstract}
In this paper, a numerical characterization of aluminum honeycomb sandwich panel and experimental validation are proposed. Firstly, numerical homogenization approach to predict the elastic properties of the core only are performed using initial finite element model of Representative Volume Element (RVE) which does not take into account the double thickness wall existing in aluminum core structure. According to these initial parameters, finite element model of sandwich composite plate is constructed to extract its elasto-dynamic characteristics. In order to validate the numerical achievements, Experimental Modal Analysis of sandwich plate was carried out. Secondly, the double thickness wall is selected to be introduced in the RVE because of important error between results, new comparative study validates the improved elastic parameters and illustrate that the double thickness wall play an important role in the homogenization procedure. Furthermore, the influence of the delamination defect on the vibration behavior of the composite panel is investigated using the validated 3-D finite element model.
\end{abstract}

KEYwORDS. Homogenization; Honeycomb sandwich; Frequency; Mode shape; Experimental modal analysis; Delamination.

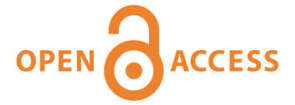 \\ Citation: Bendada, A., Boutchicha, D., \\ Chouiter, A., Miri, M., Numerical- \\ Experimental characterization of honeycomb \\ sandwich panel and numerical modal analysis \\ of implemented delamination, Frattura ed \\ Integrità Strutturale, 49 (2019) 655-665. \\ Received: 06.03.2019 \\ Accepted: 15.06.2019 \\ Published: 01.07.2019 \\ Copyright: (C) 2019 This is an open access \\ article under the terms of the CC-BY 4.0, \\ which permits unrestricted use, distribution, \\ and reproduction in any medium, provided \\ the original author and source are credited.
}

\section{INTRODUCTION}

$\mathrm{H}$ oneycomb sandwich panels are finding its use in many fields such as thermal and structural applications. These panels are extensively used in structural applications due to their properties such as high strength to weight ratio, high energy absorbing capacity, bending stiffness etc. Due to such properties honeycomb panels are used for design and construction of lightweight transportation systems such as satellites, aircrafts, rocket fins, high speed trains, fast ferries where structural weight reduction is of prime importance. In order to use these materials in different applications, the knowledge of their mechanical behaviour is required. This calls for the development of rigorous mathematical and experimental methods capable of characterizing, modelling, designing and optimizing of the composite under any given set of conditions. Numerical simulation of these structures requires, firstly, a proper experimental 
identification of the core and the skins material behaviours, and secondly an adequate kinematic model to obtain a reasonable computational cost. For reasons of characterizing the honeycomb core, the cellular core is replaced by a quasihomogeneous medium, and the sandwich theory can be adopted to analyze the sandwich structure [1], In 1958 Kelsey first provided a set of equations for $G_{x z}$ and $G_{y z}$ based on energy methods applied on the honeycomb cell walls[2]. Gibson and Ashby extended this analytical approach to drive all the nine orthotropic parameters [3]. Other improvement of theorical model proposed by Masters and Evans for predicting the in-plane elastic stiffness of honeycomb cores based on deformation of honeycomb cells [4]. Xu et al presented another investing approach [5]. Chen and Davalos improved an analytical model to calculate the modulus and interface constraints for extension problems [6]. A new analytical method to analyze the out-of-plane stiffness of honeycomb cores based on the modified laminate theory proposed by Meraghni et al [7]. Hu and al presented a complete review of the various Kinematics and theories concerning the sandwich composite modeling [8] Experimental methods on testing the elastic properties of honeycomb core have been developed. Young's moduli in the thickness direction were determined by compression tests [9]. Cunningham et al proposed a new measurement technique for estimating the shear strain in a totally enclosed core [10]. Saito et al considered an aluminium honeycomb sandwich panel as an orthotropic Timoshenko beam for identifying the corresponding parameters by solving the least squares problems by a non-linear optimization method [11]. Finite element model of e Representative Volume Element (RVE) of more complicated honeycomb sandwich cores [12] can be constructed to predict the elastic equivalent properties $[13,14]$. In the past decades, many researchers have studied the vibration of sandwich structures. Kerwin proposed a new theoretical model which is developed for the damping in sandwich structure [15]. By varying the thickness and materials of the skins, it's possible to obtain a desired performance, particularly high strength and stiffnessto-mass ratio [16-18].

The objective of present paper is to carry out a comparative study on numerical and experimental techniques capable of predicting the mechanical parameters of honeycomb core. For initial prediction; the analytical Gibson and Ashby formulations are used for determining the constants parameters that will be compared with numerical homogenization results. Once the honeycomb core is homogenized, the whole sandwich panel constituted of three elastic layers: isotropic/orthotropic/isotropic was created using the finite element code ANSYS and numerical modal analysis was performed. In order to validate the accuracy of the numerical approach, experimental modal analysis was carried out. According to the important error between numerical-experimental results, the inaccurate initial elastic constants need to be improved. In reality, the aluminum honeycomb core contains the double cell wall which is not taken into account in the initial RVE. So, the in-plane parameter $G_{x y}$ and out-of plane parameters $E_{z}, G_{y z}$ were selected to be estimated again by a new RVE which takes into consideration the double thickness wall. Comparison between the measured and the new computed eigenvalues and the corresponding eigenmodes shows the good agreement and minimized error which confirms the improved properties and the 3D model of panel that will be used for the next numerical analysis to predict the influence of the delamination on the structure rigidity.

\section{HOMOGENIZATION PROCEDURE}

\section{The classical Gibson method}

7 he analytical expressions (Tab. 1) used for the elastic properties prediction of honeycomb core which is assimilated to an orthotropic material, are based on the important research of [3] where $E_{S}$ and $v_{S}$ present the Young modulus and Poisson's ratio of the cell material. The unit cell of the honeycomb core is a regular hexagon (Fig.1) of dimensions: $t=0.08 \mathrm{~mm}, h=11.085 \mathrm{~mm}, \theta=30^{\circ}$, density of $29 \mathrm{Kg} / \mathrm{m}^{3}$ and W-oriented configuration.

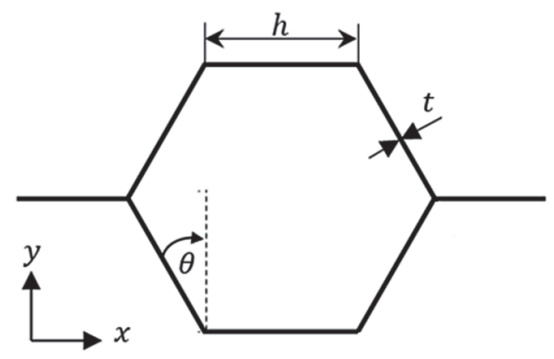

Figure 1: Unit regular hexagon cell of honeycomb with simple wall. 
In-plane (x, y) parameters

$E_{x}$ :Young modulus in $x \quad E_{S}\left(\frac{t}{l}\right)^{3} \frac{\left(\frac{h}{l}+\sin \theta\right)}{\cos ^{3} \theta}$

$E_{y}$ :Young modulus in $y$ direction

$$
E_{S}\left(\frac{t}{l}\right)^{3} \frac{\cos \theta}{\left(\frac{b}{l}+\sin \theta\right) \sin ^{2} \theta}
$$

$G_{x y}$ :Shear modulus in $x y$ plane

$$
E_{S}\left(\frac{t}{l}\right)^{3} \frac{\left(\frac{b}{l}+\sin \theta\right)}{\left(\frac{b}{l}\right)^{2}\left(1+\frac{2 b}{l}\right) \cos \theta}
$$

Poisson's ratio $v_{x y}$

$$
\frac{\left(\frac{b}{l}+\sin \theta\right) \sin \theta}{\cos ^{2} \theta}
$$

Poisson's ratio $v_{y x} \quad \frac{\cos ^{2} \theta}{\left(\frac{b}{l}+\sin \theta\right) \sin \theta}$

\section{Out-of-plane parameters}

$E_{z}$ :Young modulus in z direction

$$
E_{S}\left(\frac{t}{l}\right) \frac{\left(\frac{h}{l}+2\right)}{2\left(\frac{h}{l}+\sin \theta\right) \cos \theta}
$$

$G_{y z}:$ Shear modulus in $G_{S}\left(\frac{t}{l}\right) \frac{\cos \theta}{\frac{b}{l}+\sin \theta}$

$G_{x z}$ Shear modulus in $G_{S}\left(\frac{t}{l}\right) \frac{\frac{b}{l}+\sin \theta}{\left(1+\frac{2 l}{b}\right) \cos \theta}$

Poisson's ratio $v_{y z} \quad \frac{E_{y}}{E_{z}} v_{s}$

Poisson's ratio $v_{x z} \quad \frac{E_{x}}{E_{z}} v_{s}$

Table 1: Equivalent elastic properties of honeycomb core of Gibson.

\section{Numerical approach}

In this study, an elaborated ANSYS program makes it possible to build the RVE model consisting of 40 cells of dimensions $l_{x}=166.27 \mathrm{~mm}, l_{y}=86.4 \mathrm{~mm}, l_{z}=8.8 \mathrm{~mm}$, as shown in Fig. 2, the material properties of the core are presented in Tab. 2. The numerical homogenization method consists of series of simulations carried out on the RVE.

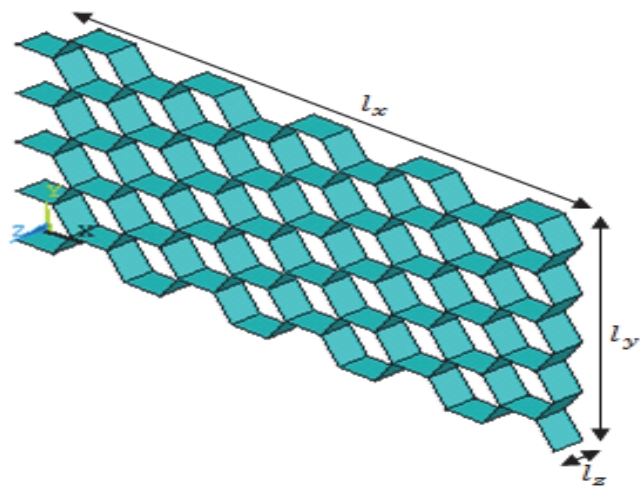

Figure 2: Initial RVE model.

\begin{tabular}{lc}
\hline Density $(\rho)$ & $2700 \mathrm{Kg} / \mathrm{m}^{3}$ \\
Poisson's ratio & 0.34 \\
Young modulus & $69000 \mathrm{MPa}$ \\
\hline
\end{tabular}

Table 2: Material properties.

The RVE model is meshed using shell element. Three extension simulations in the directions $x, y$, z were applied on the RVE to estimate Young's moduli $E_{x}, E_{y}, E_{z}$ and Poisson's ratios $v_{x y}, v_{y z}, v_{x z}$. Young's moduli are determined using the tensile behavior relations ships of uniaxial linear elasticity with simple transformations:

$$
\sigma_{i}=E_{i} \varepsilon_{i}=\frac{F_{i}}{S_{i}}
$$


where $F_{i}$ is the applied force on the RVE when the displacement $\delta U_{i}$ is imposed, $\mathrm{S}_{\mathrm{i}}$ is the perpendicular surface to the displacement.

Poisson's ratios are determined by the following equation:

$$
v_{i j}=-\frac{\varepsilon_{j}}{\varepsilon_{i}} \text { with } i \neq j \quad i, j=x, y, z
$$

where the deformations $\varepsilon_{i}, \varepsilon_{j}$ are given by the following equations:

$$
\varepsilon_{i}=\frac{\delta U_{i}}{l_{i}} \text { and } \varepsilon_{j}=\frac{\delta U_{j}}{l_{j}}
$$

with $l_{i, j}$ represents the length, thickness and width of the RVE.

The boundary conditions applied in each case for identifying the Young's moduli are given in Tab. 3, Tab. 4 presents the deformation of the RVE in each extension numerical simulation.

\begin{tabular}{llllll}
\hline \multicolumn{2}{c}{$x$ direction } & \multicolumn{2}{c}{$y$ direction } & \multicolumn{2}{c}{ direction } \\
$x=0$ & $U_{x}=0.0 \mathrm{~mm}$ & $y=0$ & $U_{y}=0.0 \mathrm{~mm}$ & $z=0$ & $U_{z}=0.0 \mathrm{~mm}$ \\
$x=L_{x}$ & $U_{x}=1.0 \mathrm{~mm}$ & $y=L_{y}$ & $U_{y}=1.0 \mathrm{~mm}$ & $z=L_{z}$ & $U_{y}=0.1 \mathrm{~mm}$ \\
$y=L_{y} / 2$ & $U_{y}=0.0 \mathrm{~mm}$ & $x=L_{x} / 2$ & $U_{x}=0.0 \mathrm{~mm}$ & $x=L_{x} / 2$ & $U_{x}=0.0 \mathrm{~mm}$ \\
$z=L_{z} / 2$ & $U_{z}=0.0 \mathrm{~mm}$ & $z=L_{z} / 2$ & $U_{z}=0.0 \mathrm{~mm}$ & $y=L_{y} / 2$ & $U_{y}=0.0 \mathrm{~mm}$ \\
\hline
\end{tabular}

Table 3: Extension boundary conditions.

$x$ direction

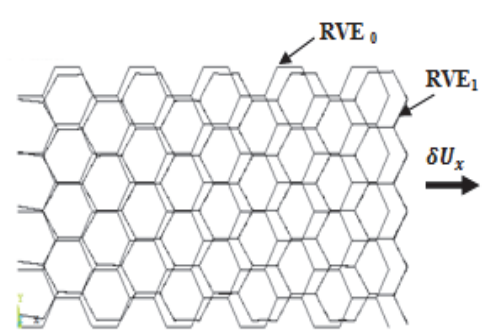

(a) $y$ direction

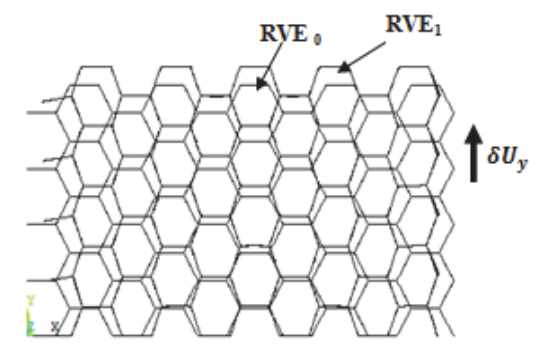

(b) z direction

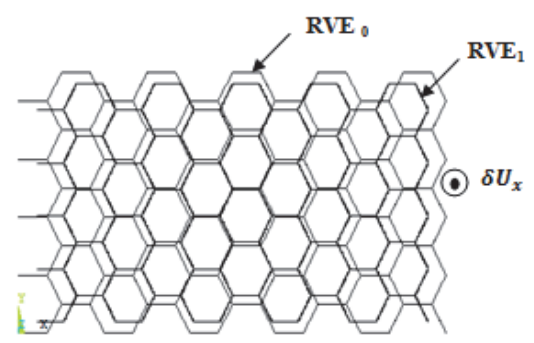

(c)

Table 4: $\mathrm{RVE}_{0}$ undeformed shape, $\mathrm{RVE}_{1}$ deformed shape, in each case of extension simulation.

Shear moduli $G_{x y}, G_{x y}, G_{y z}$ are determined by the equation:

$$
G_{i j}=\frac{I_{i} F_{i}}{S_{i k} \delta U_{i}}, i \neq j \neq k, S_{i k}=l_{i} \times l_{k}
$$

$F_{i}$ is the resulting shear forces in direction $i$ by applying the displacement $\delta U_{i}$ along the directions $x, y$, $z$. The boundary conditions and deformation shape are given in Tab. 5-6. 


\begin{tabular}{|c|c|c|c|c|c|}
\hline \multicolumn{2}{|c|}{$G_{x y}$} & \multicolumn{2}{|c|}{$G_{x z}$} & \multicolumn{2}{|r|}{$G_{y z}$} \\
\hline \multirow{3}{*}{$y=0$} & $U_{x}=0.0 \mathrm{~mm}$ & \multirow{3}{*}{$z=0$} & $U_{x}=0.0 \mathrm{~mm}$ & \multirow{3}{*}{$z=0$} & $U_{x}=0.0 \mathrm{~mm}$ \\
\hline & $U_{y}=0.0 \mathrm{~mm}$ & & $U_{y}=0.0 \mathrm{~mm}$ & & $U_{y}=0.0 \mathrm{~mm}$ \\
\hline & $U_{z}=0.0 \mathrm{~mm}$ & & $U_{z}=0.0 \mathrm{~mm}$ & & $U_{z}=0.0 \mathrm{~mm}$ \\
\hline \multirow{3}{*}{$y=L_{y}$} & $U_{x}=1.0 \mathrm{~mm}$ & \multirow{3}{*}{$z=L_{z}$} & $U_{x}=1.0 \mathrm{~mm}$ & \multirow{3}{*}{$z=L_{z}$} & $U_{x}=0.0 \mathrm{~mm}$ \\
\hline & $U_{y}=0.0 \mathrm{~mm}$ & & $U_{y}=0.0 \mathrm{~mm}$ & & $U_{y}=1.0 \mathrm{~mm}$ \\
\hline & $U_{z}=0.0 \mathrm{~mm}$ & & $U_{z}=0.0 \mathrm{~mm}$ & & $U_{z}=0.0 \mathrm{~mm}$ \\
\hline
\end{tabular}

Table 5: Shear boundary conditions.

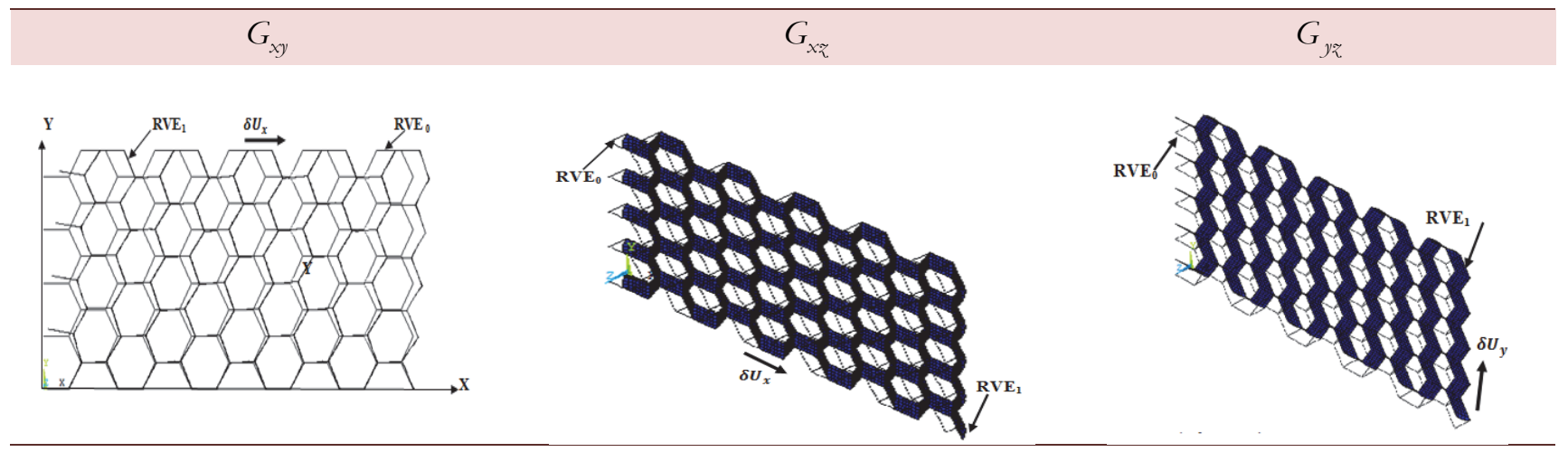

Table 6: $\mathrm{RVE}_{0}$ undeformed shape, $\mathrm{RVE}_{1}$ deformed shape in each case of shear simulation.

\section{Analytical and numerical results}

In Tab. 7, comparison between analytical and numerical results. It's clearly seen that the obtained numerical equivalent parameters give a good agreement.

\begin{tabular}{cccc}
\hline $\begin{array}{c}\text { Constant } \\
\text { parameters }\end{array}$ & Gibson & ANSYS & $\begin{array}{c}\text { Error } \\
(\%)\end{array}$ \\
$E_{x}(M P a)$ & $5.989 \times 10^{-2}$ & $5.99 \times 10^{-2}$ & 0.016 \\
$E_{y}(M P a)$ & $5.989 \times 10^{-2}$ & $5.96 \times 10^{-2}$ & 0.484 \\
$E_{z}(M P a)$ & 575.006 & 594.167 & 3.33 \\
$G_{x y}(M P a)$ & $1.497 \times 10^{-2}$ & $1.475 \times 10^{-2}$ & 1.46 \\
$G_{x z}(M P a)$ & 107.277 & 113.223 & 5.54 \\
$G_{y z}(M P a)$ & 107.277 & 105.645 & 1.52 \\
$v_{x y}$ & 1 & 1 & 0.00 \\
$v_{y z}$ & $3.54 \times 10^{-5}$ & $3.33 \times 10^{-5}$ & 5.93 \\
$v_{x z}$ & $3.54 \times 10^{-5}$ & $3.36 \times 10^{-5}$ & 5.08 \\
\hline
\end{tabular}

Table 7: Equivalent elastic properties of honeycomb core.

\section{NUMERICAL MODAL ANALYSIS}

$\mathrm{T}$

o study the vibrational behavior of completely free honeycomb sandwich plate, 3-D model of panel is built and consists of thick core which is homogenized to orthotropic volume in the previous section, and thin face sheets joined with a core (Fig. 3). It is meshed using solid element (SOLID185, BRICK 8node185) and consisted of 4620 
nodes and 2592 elements. Geometric dimensions of the panel are shown in Tab. 8. The skins and the core are made of an aluminum alloy (Tab. 2).

\begin{tabular}{cccc}
\hline & Length $(\mathrm{mm})$ & Width $(\mathrm{mm})$ & Thick $(\mathrm{mm})$ \\
Core & 250 & 210 & 8.8 \\
Skin & 250 & 210 & 0.6 \\
\hline
\end{tabular}

Table 8: Geometric dimensions of the panel.

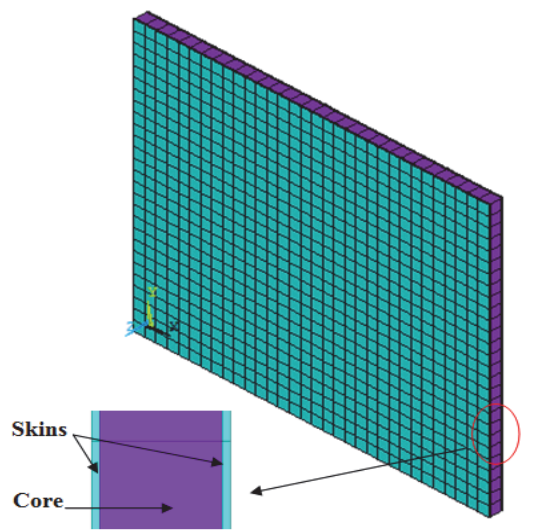

Figure 3: Numerical model of honeycomb sandwich panel.

\section{EXPERIMENTAL VALIDATION}

7 he non-destructive testing (NDT) is crucially important for composite structures during manufacturing, as well as in-service maintenance and repair and it play a fundamental role in the characterization of composite materials [19-21]. In this study, For the experimental modal procedure, the honeycomb sandwich plate surface is marked by $5 \times 5$ parallel grid points with the size of each element is $62.5 \mathrm{~mm} \times 52.5 \mathrm{~mm}$. To avoid the boundary effects and presence of any other errors in free-free boundary condition experimental study, the structure is vertically suspended by flexible strings. Fig. 4 shows the modal testing setup which is executed by exciting all marked points of the panel using a PCB086C03 impulse hammer whose sensitivity is $2.25 \mathrm{mV}$. Consequently, a PCB356A15 accelerometer is fixed inside the structure at marked point number 1. A frequency response analyzer, NATIONAL INSTRUMENTS (NI) cDAQ-9184 executed the signal acquisition and conditioning. Finally, the frequency response functions (FRF) measurements (Fig.5) and associated mode shape are obtained.

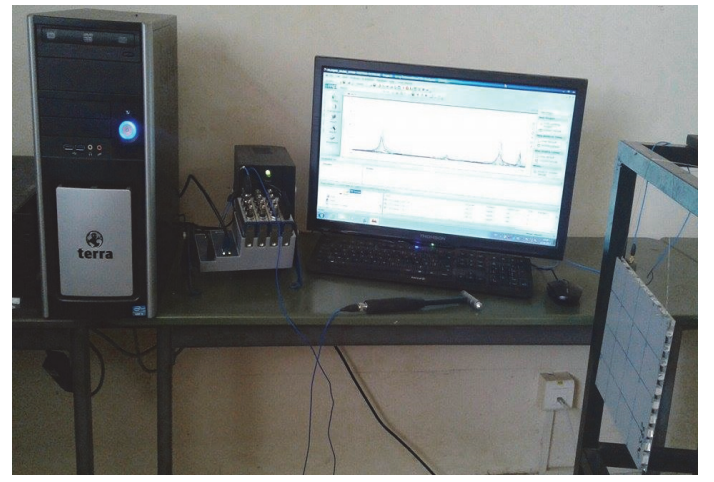

Figure 4: Experimental set-up.

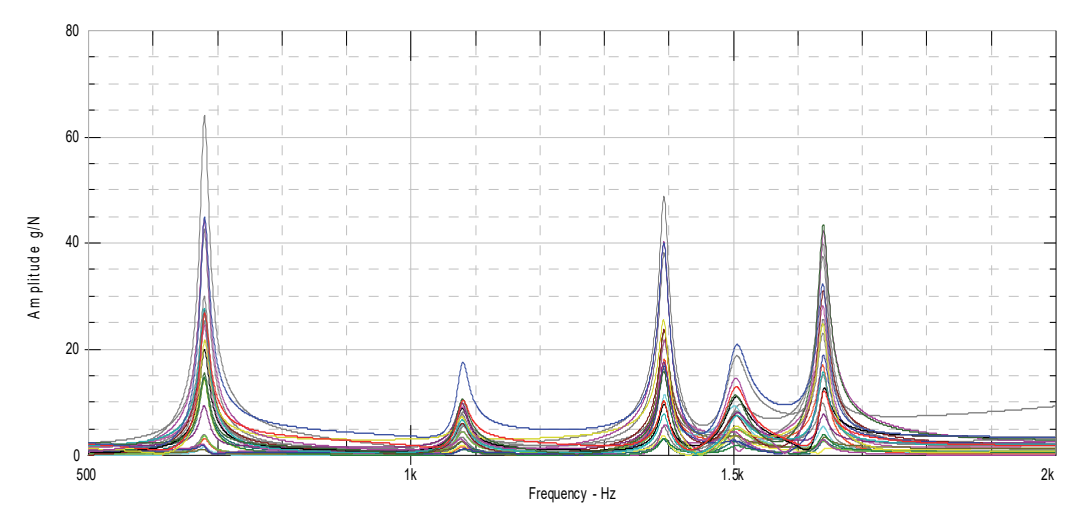

Figure 5: FRF measurements at 25 different grid points. 


\section{Initial comparative study}

Tab. 9 shows the mode shapes achieved via experimental modal analysis and finite element analysis.

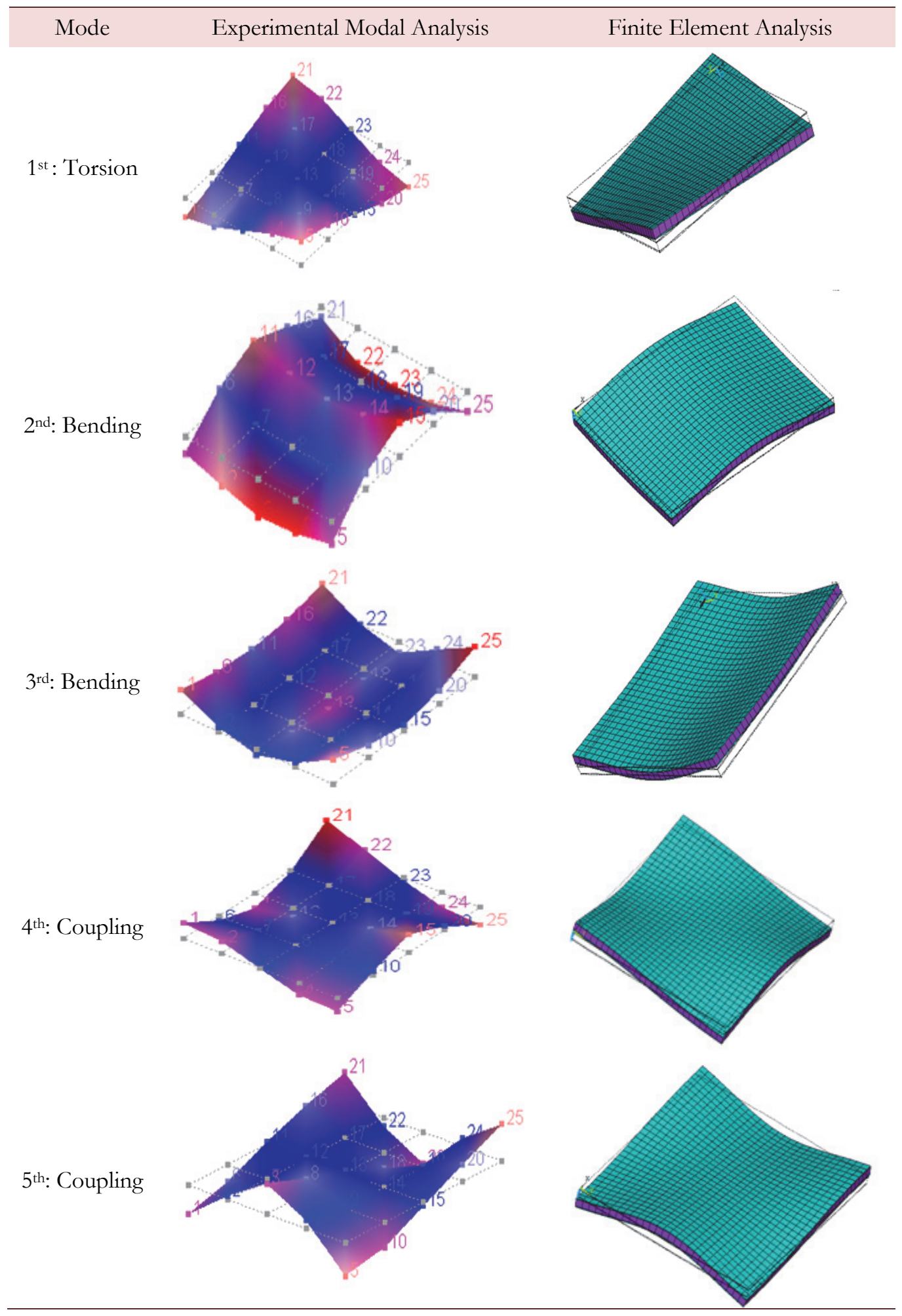

Table 9: Experimental and numerical mode shapes for a completely free honeycomb sandwich panel. 


\begin{tabular}{cccc}
\hline Mode order & Experimental results $(\mathrm{Hz})$ & Numerical results $(\mathrm{Hz})$ & Error \% \\
1 & 680.82 & 712.29 & 4.60 \\
2 & 1081.42 & 1095.30 & 1.20 \\
3 & 1393.90 & 1506.00 & 8.00 \\
4 & 1511.35 & 1526.10 & 0.97 \\
5 & 1638.42 & 1747.30 & 6.64 \\
\hline
\end{tabular}

Table 10: Comparison between experimental and numerical results for simple thickness wall.

It can be observed from Tab. 9 that the mode shapes measured by experimental and numerical modal analysis are very much alike from the visual inspection, Comparison between frequencies is shown in Tab. 10, the maximum error is 8.00 $\%$, and the mean error is $4.28 \%$, results show that the equivalent elastic properties are not so efficient for reflecting the macro-mechanical parameters of the honeycomb core, this discrepancy can be explained by the neglect of the double thickness wall existing in aluminum honeycomb core (Fig. 6) in the analytical and numerical homogenization procedure.

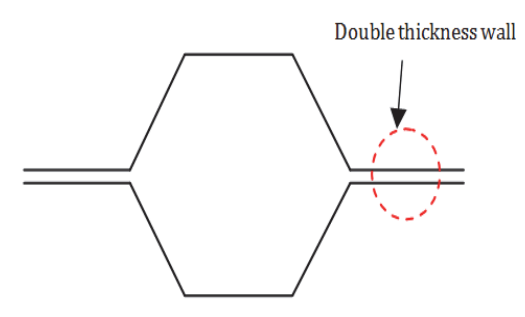

Figure 6: Double thickness wall location.

\section{Precise CONSTANT PARAMETERS}

$I^{\prime}$ $\mathrm{n}$ this step, we have modified the program by introducing the double thickness wall (Fig. 7) to recalculate $E_{z}, G_{x y}, G_{y z}$ which influenced the results [14]. Tab. 11 represents the improved elastic parameters.

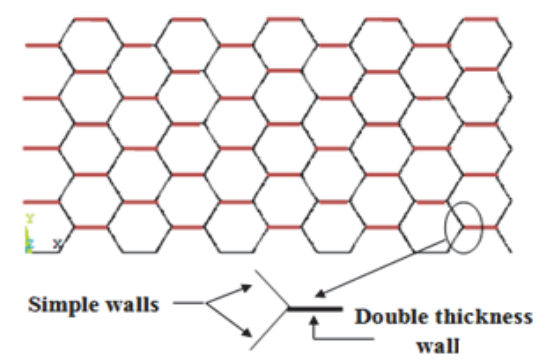

Figure 7: RVE with double wall.

\begin{tabular}{cc}
\hline$E_{z}(M P a)$ & 796.196 \\
$G_{x y}(M P a)$ & $1.169 \times 10^{-2}$ \\
$G_{y z}(M P a)$ & 88.81 \\
\hline
\end{tabular}

Table 11: Improved parameters.

Comparison between experimental frequencies and new identified results is presented in Tab. 12. The maximum error is no more than $4.5 \%$, results show that the improved orthotropic elastic properties determined on taking into account the double cell wall are appropriate.

\begin{tabular}{cccc}
\hline $\begin{array}{c}\text { Mode } \\
\text { order }\end{array}$ & $\begin{array}{c}\text { Experimental results } \\
(\mathrm{Hz})\end{array}$ & $\begin{array}{c}\text { New numerical results } \\
(\mathrm{Hz})\end{array}$ & $\begin{array}{c}\text { Error } \\
\%\end{array}$ \\
1 & 680.82 & 702.04 & 3.2 \\
2 & 1081.42 & 1091.20 & 0.9 \\
3 & 1393.90 & 1456.70 & 4.5 \\
4 & 1511.35 & 1497.50 & 0.9 \\
5 & 1638.42 & 1692.00 & 3.2 \\
\hline
\end{tabular}

Table 12: Comparison between experimental modal frequencies and new computational results. 


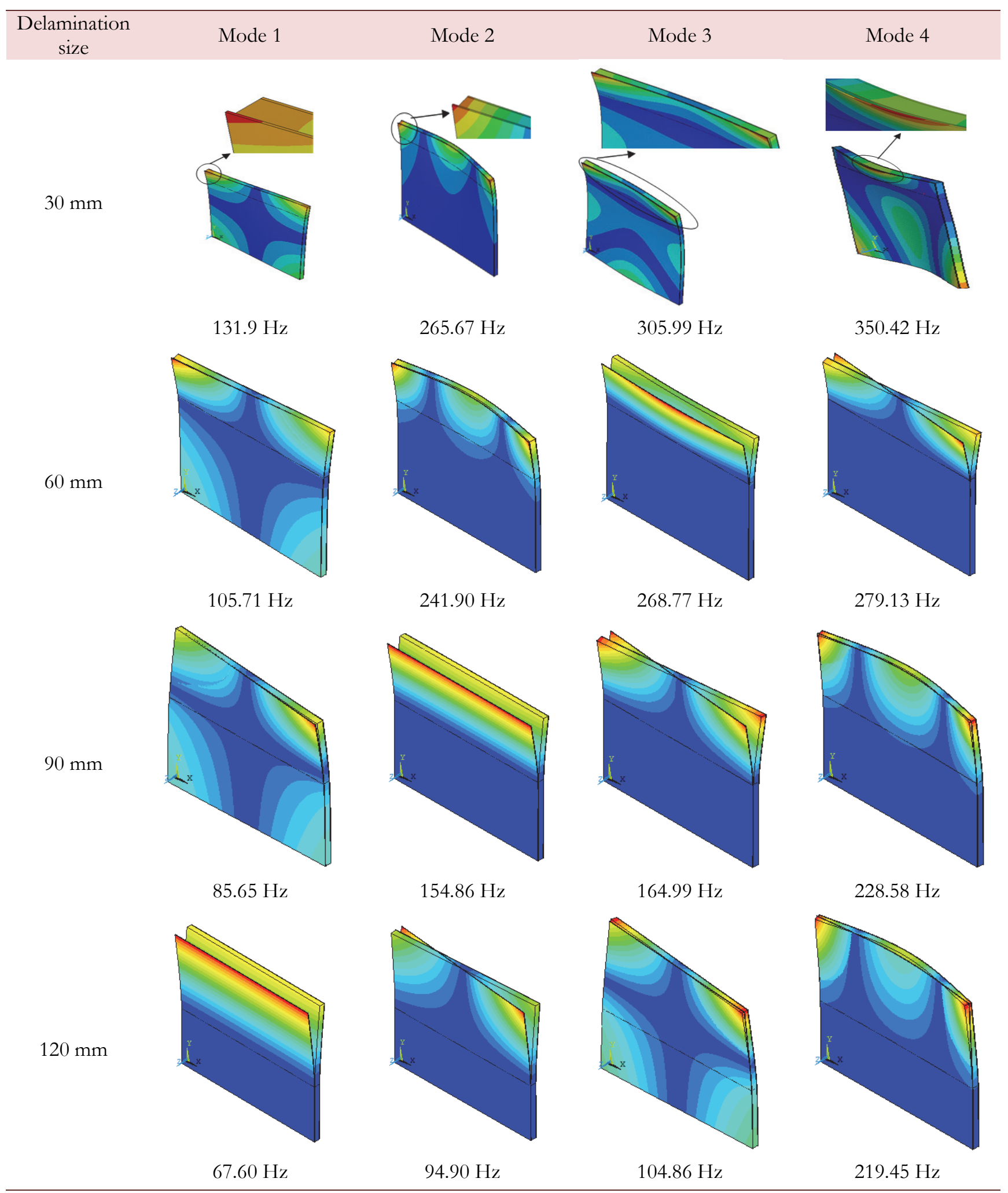

Table 13: Frequencies and corresponding mode shapes of damaged composite plate. 


\section{EFFECT OF DELAMINATION}

A continuous effort was addressing to study the vibrational behaviour of damaged composite plate using the numerically predicted parameters. The damages are inevitable in structures [22-23]; delamination is a common type of the honeycomb sandwich panel damage. In this work the detection of modal parameters of damaged honeycomb sandwich panel was carried out. We created a delamination of different size in one face only of sandwich panel. The natural frequencies and the mode shapes of a damaged model structure are obtained and presented in Tab. 13. The results show that the natural frequencies are very influenced by this defect (reduced rigidity) and new mode shapes appear in each delamination size.

\section{CONCLUSION}

$\mathrm{P}$ rediction study for determining the accurate orthotropic parameters of honeycomb aluminum core were investigated. According to the numerical equivalent properties a finite element model of honeycomb sandwich panel was created to extract the dynamical characteristic (frequencies and mode shapes), Experimental modal analysis was carried out to validate the numerical achievements. The important error between the computational results and experimental modal analysis led to introduce the double thickness wall in the Representative Volume Elements for determining the precise properties.

The good agreement of frequencies and also corresponding mode shapes between numerical and experimental results after introducing the double thickness walls shows that:

- The neglect of double wall in the characterization of pure core gives not efficient elastic properties which affects the mechanical analysis results of honeycomb sandwich panel.

- The numerical homogenization method using RVE can provide accurate equivalent elastic constants of honeycomb core.

- Non-destructive experimental method based on a precise contact free-free measurement system is very effective to validate the numerical achievements.

According to the efficient parameters, a numerical study of damaged panel model is carried out to examine the influence of delamination on the modal parameters of the structure. The results show that the natural frequencies became lower which can be explained by the degradation of structural rigidity due to delamination.

\section{REFERENCES}

[1] Hohe, J., Becker, W. (2002). Effective stress-strain relations for two-dimensional cellular sandwich cores: homogenization, materials models and properties, Appl. Mech, 55(1), 61.

[2] Kelsey, S., Gellatly, R A., Clark, B W. (1958). The shear modulus of foil honeycomb cores, Aircraft engineering, 30, pp.294-302.

[3] Gibson, L., Ashby, M F. 2 $2^{\text {nd }}$ éd., (1999). Cellular Solids: Structure and Properties, Cambridge: Cambrige Solid State Series.

[4] Masters, I G., Evans, K E. (1996). Models for the elastic deformation of honeycombs, Composite Structure, 35, pp. 403-422.

[5] Xu, X F., Qiao, P. (2002). Homogenized elastic properties of honeycomb sandwich panels with skin effect, Journal Solids and Structures, 39, pp.2153-2188.

[6] Chen, A., Davalos, J. (2005). Solution including skin effect for stiffness and stress field of sandwich honeycomb core, J Solids and Structures, 42, pp. 2711-2739.

[7] Meraghni, F., Desrumaux, F., Benzeggagh, M L. (1999). Mechanical behavior of cellular core for structural sandwich panels, Composites: Part A, 30, pp. 767-779.

[8] Hu, H., Belouettar, S., Daya, E M. (2006). Evaluation of Kinematic formulations for viscoelastically damped sandwich beam modeling, J Sandwich struct Master, 8, pp.477-495.

[9] Mujika, F., Pujana, J., Olave, M. (2011). On the determination of out-of-plane elastic properties of honeycomb sandwich panels, Polymer Testing, 30(2), pp.222-228. 
[10] Cunningham, P R., White, R G. (2001). A new measurement technique for the estimation of core shear strain in closed sandwich structures, Composites structures, 51(3), pp.319-334.

[11] Saito, T., Parbey, R D., kuno, S. O and al. (1997). Parameter identification for aluminum honeycomb sandwich panels based on orthotropic Timoshenko beam theory, Journal Sound Vibration, 208 (2), pp.271-287.

[12] Nilsson, E., Nilson, A C. (2002). Prediction and measurement of some dynamic properties of sandwich structures with honeycomb and foam cores, Journal of Sound and Vibration, 251(3), pp.409-430.

[13] Hohe, J., Becker, W. (2001). A rafined analysis of the effective elasticity tenser for general cellular sandwich cores, International journal of solids and structures,38, pp.3689-3717.

[14] Keskes, B: Compotement en fatigue des composites type sandwich nid d'abeille. Dissertation. Universté Ferhat ABBAS Algeria (2007).

[15] Kerwin, E M. (1959). Damping of flexural waves by a constrained viscoelastic layer, Journal of acoustical society of America., 31(7), pp. 952-962.

[16] Boudjemai, A., Bekhti, M., Bouanane, M H., Si Mohammed, A M., Cooper, G and Richardson, G.(2005). Small satellite computer-aided design and manufacturing, proceedings of the European conference on spacecraft structures, materials and mechanical testing, pp.181-188, SP-581.

[17] Boudjemai, A., Bouanane, M H., Si Mohammed, A M. (2007). Structural modeling and small satellite optimization, page 51, Second international congress design and modeling of mechanical systems, proceeding, pp. 12-21 march, Monastir Tunisia.

[18] Boudjemai, A., Amri, R., Mankour, A., Salem, H., Bouanane, M.H., Boutchicha, D. (2011). Modal analysis and

[19] testing of hexagonal honeycomb plates used for satellite structural design, [quick edit] materials and design doi:10.1016.

[20] Hardik, P., Jamadar N I. (2016). Modal analysis of composite structure, International journal of advancement in engineering technology, Management and Applied sciences, 3(1), pp.71-82.

[21] Asif, M., khan, M A., Khan, S., Choudhry, R Z. (2018). Identification of an effective nondestructive technique for bond defect determination in laminate composite- A technical Review, Journal of composite materials, pp.1-11.

[22] Sandeep, K. D., Akhilesh, S. (2018). Advances and researches on Non-Destructine testing: A review, Materials today:proceedings, 5(2), pp. 3690-3698.

[23] Keskes, B., Abbadi, A., Azari, Z., Bouaouadja, N. (2015). Static and fatigue characterization of nomex honeycomb sandwich panels, International Review of Civil Engineering, 6(4), pp. 81-87.

[24] Keskes, B., Menger, Y., Abbadi, A., Gilgert, J., Bouaouadja, N., Azari, Z. (2007). A Fatigue Characterization of Honeycomb Sandwich Panels With A Defect, Materials and Technology, 41(4), pp. 157-161. 